International Journal of Engineering \& Technology, $7(3.34)(2018)$ 385-387
International Journal of Engineering \& Technology
SPC
Website: www.sciencepubco.com/index.php/IJET
Research paper

\title{
Design and Fabrication of Lifting Beam for Air Pre Heater Centre Section Parts
}

\author{
Manjunathan $\mathbf{R}^{1 *}$, Gayathri $\mathrm{N}^{2}$, Muralidharan $\mathbf{M}^{3}$, Barathan $\mathbf{A}^{4}$, Delhibabu $\mathbf{R}^{5}$, Ilaiyarasu $\mathbf{T}^{6}$ \\ ${ }_{1,2,3,4,5}$ Department of Mechanical Engineering, Vel Tech High Tech Dr.Rangarajan Dr.Sakunthala Engineering College, Chennai- \\ 600042, India. \\ *Corresponding author E-mail: manjunathanmech@gmail.com*
}

\begin{abstract}
The project deals with the reduction of using multiple cranes during the lifting of the Centre section parts and introducing a new system called lifting beam. The lifting beam is designed to carry a weight of 18 - 20tons with the self weight of 2-2.5 tons ,reducing the involvement of more number of employees and eliminating the unwanted processes like gas cutting and welding during multiple crane usage, which results in making the Air pre heater (APH) to preheat the fresh Atmospheric air which takes the heat from outgoing Exhaust gas. APH is the device to improve the efficiency that is used generally in the thermal power plants, the main aim of this project also lies in making the lifting beam the versatile one which must be used for both the types of the centre section parts i.e., both the type of pre heaters that are being manufactured in the company of different power capacity of respective length 16 and 18 meters.
\end{abstract}

Keywords: Centre section parts; Air pre heater; lifting beam.

\section{Introduction}

Air pre heaters are used in thermal power plants. Many types of air pre heaters are available but in Ranipet BHEL the regenerative APH are used. Auxiliaries play vital role both in thermal power plants and process industries. APH, a boiler auxiliaries is used to recover economically the million o0f costly calories normally lost up the stack to put them back to work in the boiler are process equipment there by increasing the overall plant efficiently. BHEL is manufacturing regenerative type Air pre-heater (RAPH). For the past 30 years, BHEL with its vast experience made many improvements in (RAPH) to suit high ash Indian coal. The Air Pre Heater is defined as a heat exchanger used to transfer heat directly from hit flue gases to combustion air without the use of an intermediate heat transfer fluid. Air Pre Heaters are important auxiliary equipment in the modern industrial and power boilers.

Types of APH:

Recuperative type

1. Tubular heater

2. Plant type heater

Regenerative type

1. Rothemuhle heater

2. Lyungstrom heater

The air pre heater has three major parts.

1. Hot end

2. Rotary part

3. Cold end

Fuel saving and ability to burn low grades of fuel more efficiently are the two principal advantages of using an Air Pre heater in a steam generator. Improved combustion leaves very less carbon deposit that normally

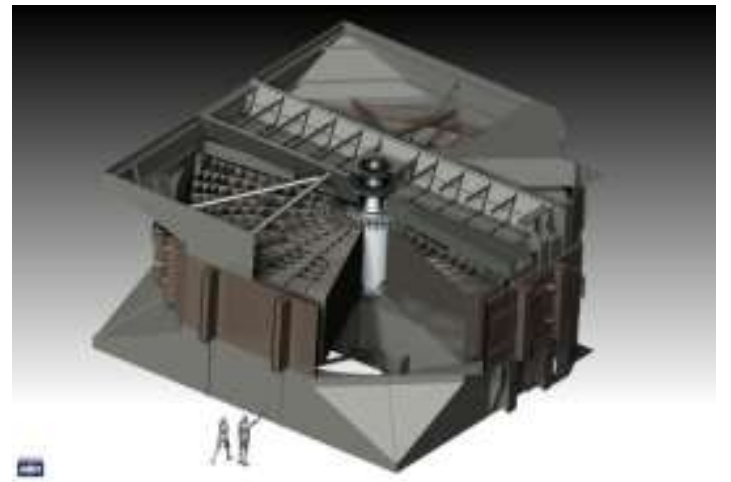

Fig. 1: Air pre heater

burning a fuel and limits the boiler output . For every $20^{\prime} \mathrm{C}$ drop in flue gas temperature (by heat recovery) the boiler efficiency will increase by $1 \%$.

At the end of the day the usage of the air pre heater also brings back the economic profit by increasing the efficiency of the air pre heater .majority of the thermal power plants on understanding the importance of the air pre heater try to update them occasionally or to repair them during their process.

\section{Experimental Study}

When we are ensuring the maximum efficiency of the plant working, there was a problem encountered during the lifting of the centre section parts (side wall and top wall).the present system included the usage of two industrial overhead cranes for the lifting purpose in which the opposite ends of the centre section parts are hanged down in the crane hooks using ropes, this also caused several other processes like welding, gas cutting etc., the existing method to eradicate this problem will be the usage of lifting beams. 
But the beams that are readily available in the market cannot be used directly because they doesn't confine with the measurements of the centre section parts so we decided to design our own lifting beam for the centre section lifting purpose which also reduces the usage of multiple cranes and the other process involved in it. U1timately the aim of the project is to design the lifting beam that saves the human time and the money.

\subsection{Lifting Beam}

The regulation says lifting beams as "work beam for lifting or lowering loads which includes its attachments for anchoring, fixing and supporting it". They also involve anything which involves the lifting of goods or people at work. Equipment covered would include lifts, cranes, ropes, slings, hooks, shackles, eyebolts, rope and pulley systems and forklift trucks.

The regulations apply to all workplaces and all the provisions of the apply to lifting equipment. A modern crawler type derrick crane with outriggers. The latticed boom is fitted with a jib. A crane is a type of machine, generally equipped with a hoist, wire ropes or chains, and sheaves, that can be used both to lift and lower material.

\section{Research Outcome}

To have a view at the solution several researches are made and also the literature surveys among all of those there are two results being concluded asusage of the $C$ (channel section) beams for the lifting beam design over the I section beam .even though the I section have the major advantages over the other section of beams available the $\mathrm{C}$ section is selected in order to prevent the major amount of material getting wasted during the hook welding process and to improve the hook efficiency that is being used in the lifting beam the usage of submerged arc welding (SAW)process during the fabrication of the beam, which will reduce the distortion in the $\mathrm{C}$ section beams during the welding. The other outcomes like the usage of the mild steel for the manufacturing of the lifting beam are also made.

\section{Design and Measurements}

There are several measurements involved in the designing of the lifting beam. The main parts are listed below.

\subsection{Side and Top Wall Measurements}

Length of side wall: $18 \mathrm{~m}$

Breadth of side wall: $0.03 \mathrm{~m}$

Height of side wall: $3 \mathrm{~m}$

Weight of side wall: 7- 8 tons

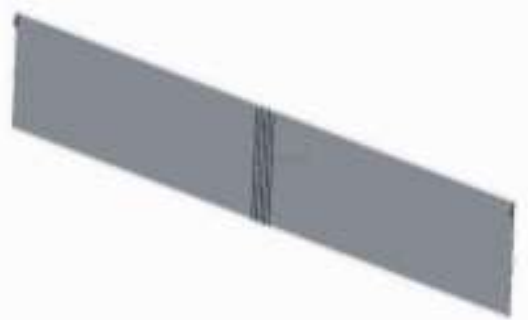

Fig. 2: Side wall
Length of top wall:
$18 \mathrm{~m}$
Breadth of top wall:
Weight of top wall:
$0.03 \mathrm{~m}$
Height of side wall: $2 \mathrm{~m}$
$18-20$ tons

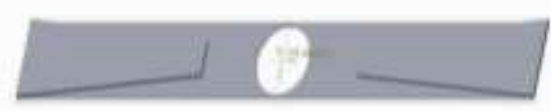

Fig. 3: Top wall

\subsection{Lifting Beam Design and Measurements}

The Measurements of lifting beam are

Length of lifting beam: $19 \mathrm{~m}$

Breadth of lifting beam: $0.43 \mathrm{~m}$

Height of lifting beam: $0.4 \mathrm{~m}$

Weight of lifting beam: 2-2.5 tons

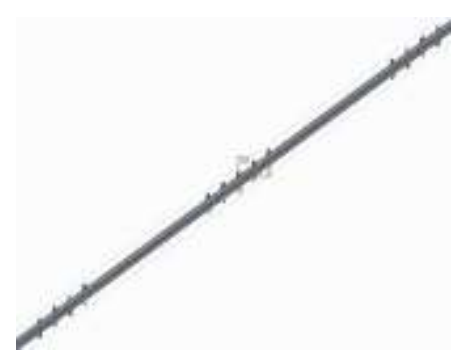

Fig. 4: 3D View of Lifting Beam

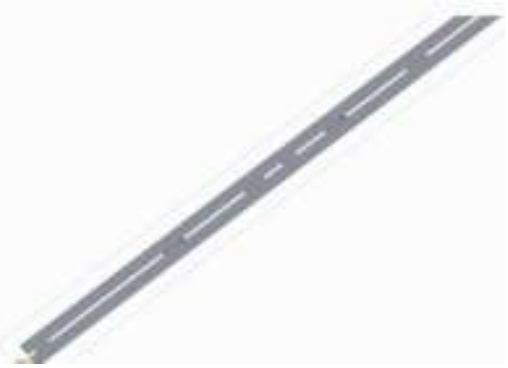

Fig. 5: Top View

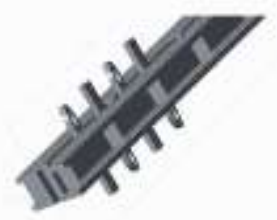

Fig. 6: Side View

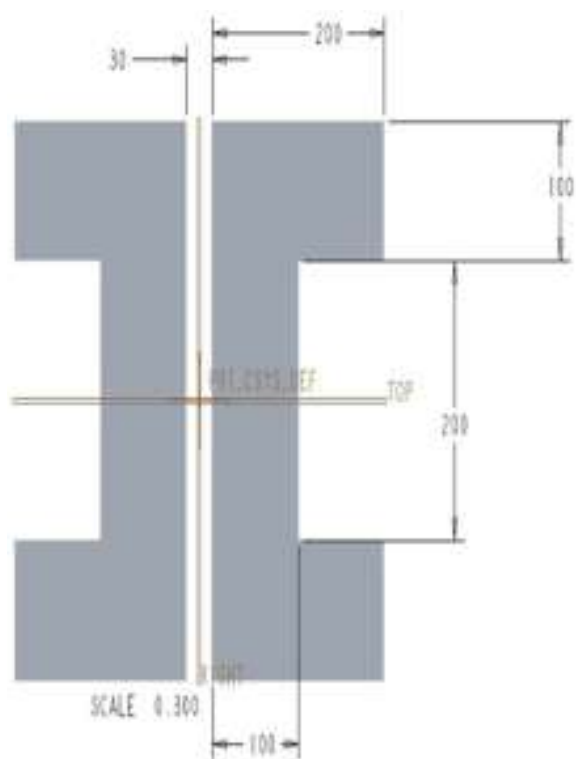

Fig. 7: Top View 


\section{Analysis and Results}

The analysis of the design and the analysis of the center section parts are done using the ANSYS to prove the safety of the design and the improved lifting efficiency in the center section parts during working.
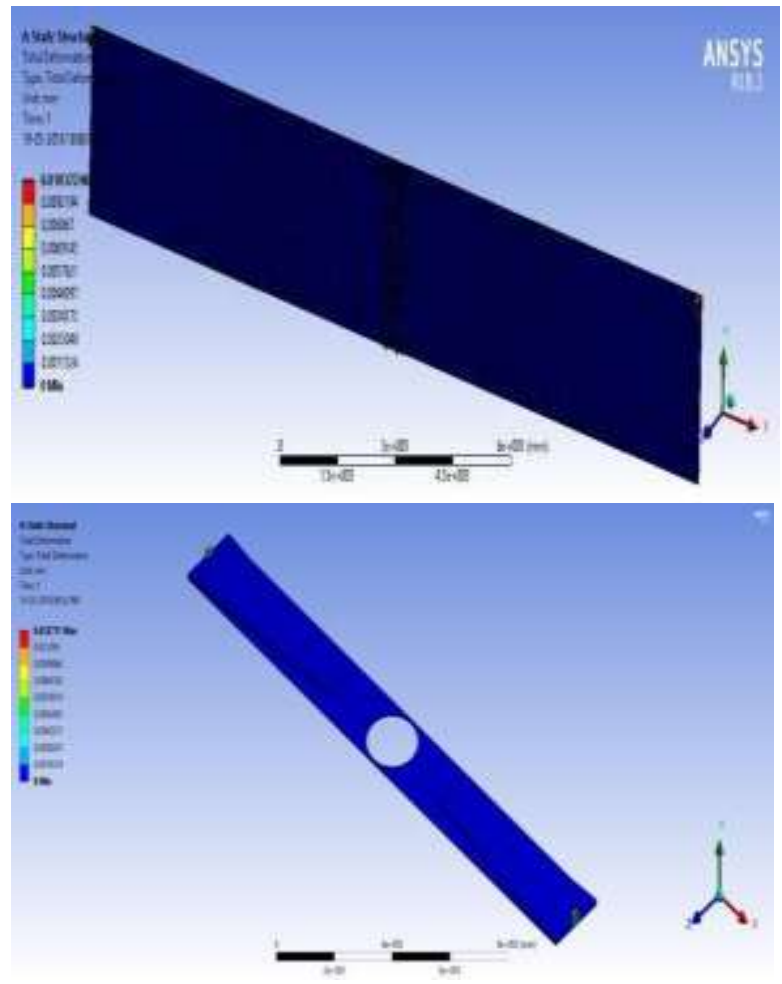

Fig. 8: Deformation of side and top walls using double cranes

This above figures shows the deformation occurred in the side and top walls of the Centre section while using two cranes

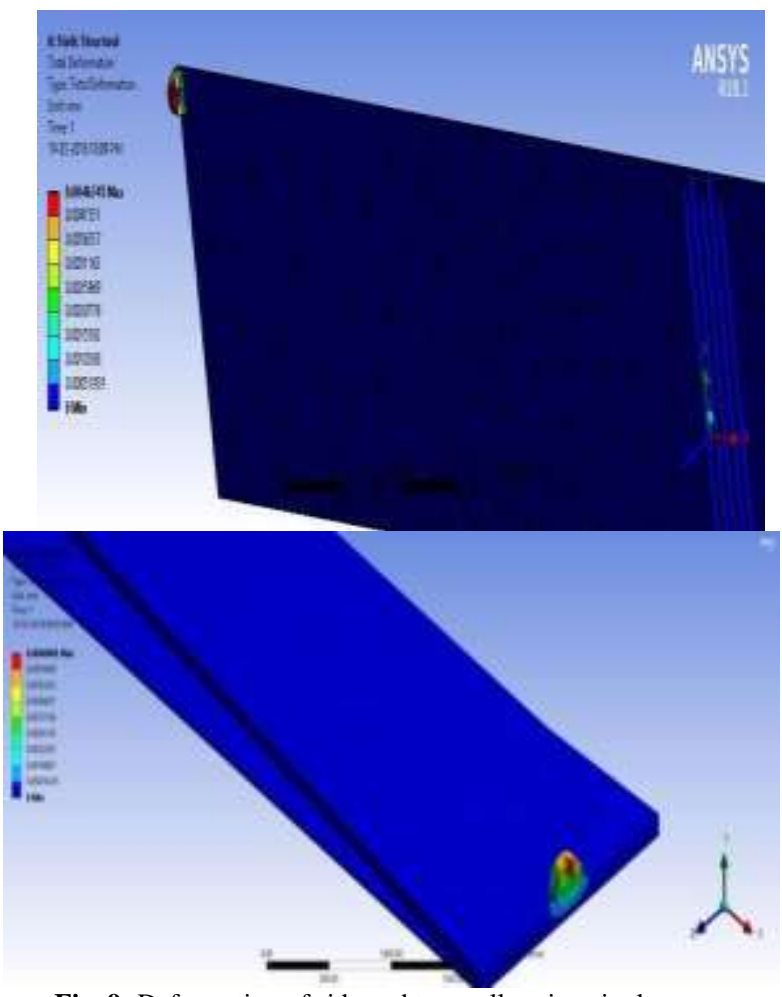

Fig. 9: Deformation of side and top walls using single crane
These above figures shows the deformation of side and top walls while using single crane

Using Two Crane:

\subsection{Deformation}

Minimum0. Mm

Maximum1.2711e-002mm Using Two Crane:

STRAIN STRESS

Min $0 . \mathrm{mm} / \mathrm{mm}-1.8003 \mathrm{Mpa}$

Max $6.8063 \mathrm{e}-005 \mathrm{~mm} / \mathrm{mm} \quad 13.613 \mathrm{Mpa}$

USING SINGLE CRANE DEFORMATION

Minimum0. Mm

Maximum0.6690e-002 mm USING SINGLE CRANE:

STRAIN STRESS

Minimum0. Mm/mm-1.0002 Mpa

Maximum3.5935e-005mm/mm 7.3072 MPa

The results prove that the efficiency increases in the lifting process when the lifting beam is used or during the usage of the single crane

\section{Advantages}

1. To reduce man power

2. To reduce the work load

3. To reduce the material handling

4. To reduce the labor cost

5. To reduce time requirement

6. To reduce fatigue of workers

7. To achieve good product quality

8. To achieve mass production

9. Usage of multiple purpose

10. Skilled persons not needed

\section{Conclusion}

Apart from the above tangible benefits, versatile lifting beam for center section provides numerous intangible benefits such as;

- It helps to reduce the man power

- It reduces the process time

- It reduces the cost of production

- Non-technical staff can overseas the process

- It also helps to carry other parts of air pre heater.

\section{References}

[1] Abdullah Sec ginb Serdar Karaog lua,. Sensitivity analysis of submerged arc welding process parameters. (10 October 2007 ) Journal of material processing technology, vol 202,issues 1-3,pp 500-507

[2] Abdullah F, Mohammed T. Hayajneh. Al-Dwairi, Sinan F. Obeidat Optimization and control of bending distortion of submerged arc welding I- beams (13 September 2017). Journal of Constructional Steel Research vol.142,pp. 78-85

[3] D. Fernando, C.M. Wang, A.N. Roy vibration of laminated-beams based on reference-plane formulation: Esupports at different heights of the beam. (4 March 2017). Engineering structures , vol 159,pp 254-251.

[4] Hong-Xia Wan, Mahen Mahendran Behaviour and strength of hollow flange channel sections under torsion and bending. (16 May 2015).Thin walled structures,vol 94,pp612-623

[5] P. N. Sapkal, P. R. Baviskar, M. J. Sable \& P. A. Makasare Optimization of Air Preheater Design for the Enhancement of Heat Transfer Coefficient. (3september2016) International journal of applied reasarch in mechanical engineering Vol 1,Issue 2, pp.176-186 